\title{
SISTEMATIZAÇÃO DA ASSISTÊNCIA DE ENFERMAGEM NA PERSPECTIVA DA EQUIPE
}

Rudval Souza da Silva ${ }^{1}$, Ana Raquel Lima Peralva de Almeida², Francieli Aparecida de Oliveira ${ }^{2}$ Arly Silva Oliveira², Maria do Rozário de Fátima Borges Sampaio ${ }^{3}$, Gilvânia Patricia do Nascimento Paixão ${ }^{4}$

Objetivo: descrever o conhecimento da equipe de enfermagem sobre a Sistematização da Assistência de Enfermagem (SAE) e o Processo de Enfermagem (PE). Metodologia: pesquisa exploratória e descritiva, realizada em 2013, com 32 profissionais de enfermagem de um hospital público do Norte da Bahia. Para a coleta de dados, foi usada a entrevista semiestruturada e os dados foram tratados segundo a técnica de análise de conteúdo de Bardin. Resultados: três categorias temáticas: 1) SAE e PE: do que estamos falando? 2) Fatores dificultadores na operacionalização do PE: com a palavra os enfermeiros 3) A formação de nível médio em enfermagem: competências e habilidade para o desenvolvimento do PE. Conclusão: existe um déficit relacionado ao conhecimento sobre a SAE e a aplicação do PE como ferramenta prática para sistematizar o cuidado de enfermagem.

Descritores: Equipe de Enfermagem; Processos de enfermagem; Administração dos cuidados ao paciente.

\section{NURSING CARE SYSTEMATIZATION IN THE PERSPECTIVE OF STAFF}

Objective: to describe the knowledge of the nursing staffs on the Nursing Care Systematization (NCS) and the Nursing Process (NP). Methodology: this is an exploratory and descriptive research, accomplished in 2013, with 32 nursing professionals from a public hospital North of Bahia. To collect data, we used the semi-structured interviews and data were treated with the technique Bardin's content analysis. Results: three thematic categories: 1) NCS and NP: what are we talking about? 2) Difficulty factors in the operationalization of the NP: with the word nurses 3) The formation of secondary level nursing: competences and skills to the development of NP. Conclusion: there is a deficit related to the knowledge of the NCS and the application of the nursing process as a practical tool to systematize nursing care.

Descriptors: Nursing team; Nursing process; Patient care management.

\section{SISTEMATIZACIÓN DE LAASISTENCIA DE ENFERMERÍA EN LA PERSPECTIVA DEL EQUIPO}

Objetivo: describir el conocimiento del personal de enfermería en la Sistematización de la Asistencia de Enfermería (SAE) y el proceso de enfermería (PE). Metodología: investigación exploratoria y descriptiva, realizada en 2013, con 32 profesionales de enfermería de un hospital público al Norte de Bahía. Para recopilar los datos, hemos utilizado las entrevistas semiestructuradas y los datos fueron tratados por la técnica de análisis de contenido de Bardin. Resultados: los tres temas: 1) SAE y PE: ¿qué estamos hablando? 2) factores que dificultan la aplicación de la PE: con la palabra los enfermeras 3) La formación de enfermería de nivel medio: las habilidades y la capacidad de desarrollar PE. Conclusión: hay un déficit en relación con el conocimiento de la SAE y la aplicación del proceso de enfermería como herramienta práctica para sistematizar los cuidados de enfermería.

Descriptores: Grupo de enfermeira; Procesos de enfermeira; Manejo de atención al paciente.

${ }^{1}$ Enfermeiro. Doutor em Enfermagem. Professor Adjunto do Colegiado de Enfermagem da Universidade do Estado da Bahia UNEB/Campus VII. E-mail: rudvalsouza@yahoo.com.br

${ }^{2}$ Acadêmica de Enfermagem da UNEB/Bolsista de Iniciação Científica/FAPESB.

${ }^{3}$ Enfermeira. Mestra em Enfermagem. Especialista em Enfermagem em Saúde Pública. Docente Aposentada do Curso de Enfermagem da Universidade Federal do Piaui (UFPI). Conselheira do Conselho Federal de Enfermagem.

${ }^{4}$ Enfermeira. Doutoranda em Enfermagem pelo Programa de Pós-Graduação em Enfermagem UFBA. Professora Assistente do Colegiado de Enfermagem da Universidade do Estado da Bahia UNEB. 


\section{INTRODUÇÃO}

A Enfermagem tem como objeto de trabalho a pessoa que necessita de cuidado, o qual deveserprestado demodo integral e individual. Para tanto, necessita de uma organização. Nessa perspectiva, a Sistematização da Assistência de Enfermagem (SAE) é a estrutura de organização que visa dinamizar o trabalho da equipe de enfermagem, direcionando as práticas de cuidar de maneira planejada e individualizada, de forma a buscar atender as particularidades de cada cliente/clientela (pessoa, família ou comunidade) $)^{(1)}$.

O Cofen, por meio da Resolução no 358/2009, normatiza a implementação da SAE em todos os ambientes, públicos e privados, onde ocorra o cuidado profissional de enfermagem, lançando mão do Processo de Enfermagem (PE). Esse é definido como uma metodologia de trabalho que visa oferecer subsídios ao desenvolvimento da assistência, tendo como base o método científico. Tem como propósito a identificação de uma situação problema de um cliente/clientela, possibilitando, assim, direcionar a implementação adequada das terapêuticas de enfermagem ${ }^{(2,3)}$. O PE é uma ferramenta operacional que visa promover a autonomia e cientificidade profissional do enfermeiro, visando aperfeiçoar a interação paciente-profissional, com o intuito de facilitar a obtenção de dados necessários para um cuidar individualizado ${ }^{(4)}$.

Estudos apontam que, de fato, ainda são marcantes as dificuldades enfrentadas pelos enfermeiros na operacionalização da SAE, destacando-se como obstáculos o número reduzido de profissionais, a sobrecarga do trabalho e o desconhecimento do funcionamento do processo de implantação da SAE pelo enfermeiro e a operacionalização do Processo de Enfermagem ${ }^{(5,6)}$. Para tanto, é evidente a necessidade de implantação da SAE em seu ambiente de trabalho e o conhecimento sobre sua utilização(7).

A relevância do estudo se apoia no pressuposto de que a partir do momento em que os profissionais compreendam o contexto da sua prática, isso poderá provocar reflexões que venham contribuir com a melhoria da qualidade da assistência na instituição lócus da pesquisa, bem como no âmbito de outros serviços de enfermagem que ainda não contemplem uma prática sistematizada.

Apesar do reconhecimento, por parte do enfermeiro e sua equipe, da relevância do PE para a organização do trabalho, na prática, ainda é visivel a resistência da equipe de enfermagem à operacionalização de uma assistência sistematizada, justificando a realização do presente estudo, o qual tem como objetivo descrever o conhecimento da equipe de enfermagem sobre a SAE e o PE.

\section{METODOLOGIA}

Estudo exploratório e descritivo de abordagem qualitativa, desenvolvido a partir de um projeto de iniciação científica, o qual teve como lócus um serviço hospitalar situado na região Piemonte Norte do Itapicuru, no estado da Bahia. Dos 56 profissionais de enfermagem da instituição, 32 participaram do estudo. Constituiu critério de inclusão trabalhar há mais de seis meses na instituição.

A coleta de dados foi realizada no período de agosto a dezembro de 2013, por meio de entrevista semiestruturada, gravada e posteriormente transcrita e analisada, enfocando o conhecimento da equipe de enfermagem sobre a SAE e o PE.

As entrevistas foram analisadas seguindo a Técnica de Análise de Conteúdo(8), o que possibilitou a organização dos dados em categorias temáticas de modo a conduzir a um resultado estruturalmente elaborado do seu conteúdo.

O processo de análise seguiu as seguintes etapas: 1. Pré-análise: partiu do processo de leitura flutuante, quando o conteúdo das respostas pôde se tornar mais claro, possibilitando estabelecer, na etapa seguinte, as unidades de registro. 2. Exploração do material: foi possivel identificar as unidades de registro por meio dos recortes das falas dos entrevistados, as quais foram codificadas em unidades de contexto. 3. Inferência: nesta última etapa, ocorreu o processo de inferência a partir das unidades de contexto, o que permitiu a categorização das ideias em categorias temáticas.

O projeto foi aprovado pelo CEP/UNEB recebendo o parecer de $n^{\circ} 246.615$ e conduzido conforme a Resolução CNS n466/12. Para garantir o anonimato, os fragmentos citados foram identificados com as letras "E" para enfermeiros [El...E8], "T" para técnicos [T1...T21] e "A" para auxiliares de enfermagem [Al...A3].

\section{RESULTADOS}

Em relação à caracterização dos 32 participantes, oito eram enfermeiros, 21 técnicos e três auxiliares de enfermagem. Em relação ao sexo, 29 são do sexo feminino e três do masculino. Quanto ao tempo de atuação dos enfermeiros, variou entre um e cinco anos e os técnicos e auxiliares de enfermagem, entre um e 30 anos de serviço. Quanto ao tempo de formação, variou entre três a dez anos e de dois a 30 anos respectivamente. Da análise dos depoimentos, emergiram três categorias temáticas apresentadas a seguir e sustentadas nas falas dos entrevistados.

\section{Categoria 1 - SAE e Processo de Enfermagem: do que estamos falando?}

Essa categoria emergiu das respostas sobre o significado de SAE e PE, o que demonstra o desconhecimento desses conceitos, evidenciando que, na formação de nível técnico, não existe uma discussão sobre tais conceitos, como pode ser 
observado nas falas a seguir: Processo de enfermagem? Não, ainda não ouvir falar não (T-7); O processo de enfermagem, em questão de cuidar. É o cuidar, o medicar, é lidar com o ser humano (T-29); Trabalhar, com gente que precisa, gente doente $(A-2)$.

Quanto aos enfermeiros, seis desses, ao responderem sobre o que compreendem em relação ao conceito de SAE e PE, demonstraram superficialidade nas definições. Meio de organização que o enfermeiro tem para liderar sua prática e fornecer autonomia profissional aos cuidados especificos aos pacientes (E-11); Etapas para organização da assistência humanizada da enfermagem (E-12).

Três enfermeiros conseguiram expressar elementos conceituais que nos possibilitam inferir o que reflete as definições postas na Resolução 358/2009. São os instrumentos que a gente utiliza, [...] para organizar utilizando do PE para um cuidado individualizado, utilizando além de várias etapas outros recursos também (E-13); De acordo com esse PE é que a gente vai preparar o nosso cuidado com o paciente, que nesse processo a gente acaba que entrando meio que na sistematização. Se eu sei o que eu vou fazer com o meu paciente eu vou sistematizar o meu atendimento (E-14); É um retrato de todo o serviço de enfermagem, é o retrato do trabalho do enfermeiro com sua equipe. Viabiliza a questão financeira, dos gastos da empresa também, é um ponto positivo dela, trazer economias pra empresa porque você tem como melhor planejar o serviço durante o mês, conhecendo seu público (E-16).

\section{Categoria 2 - Fatores dificultadores na operacionalização do PE: com a palavra os enfermeiros}

Nessa categoria, puderam ser evidenciados os fatores dificultadores como o número reduzido de enfermeiros, a ausência de educação permanente, além do desconhecimento e inabilidade na operacionalização das etapas do PE. Como dificultador é a necessidade dos próprios recursos humanos pra que haja tempo para implantação da sistematização, [...] uma vez implantado realizar uma educação continuada, uma conscientização, uma apresentação pra toda equipe que muitas vezes eles desconhecem (E-1); A gente fica muito presa às burocracias [do serviço]. Dificulta você olhar o paciente, tocar, fazer anamnese, fazer o exame físico, porque muitas vezes a gente está na mesa, cuidando só da parte burocrática do hospital (E-13); A quantidade de profissionais, a gente não tem o suficiente pra fazer o PE [...] (E-16); Tem que implantar o SAE na unidade e botar em prática, porque aqui não funciona (E-22).

Apenas dois enfermeiros reconhecem explicitamente a importância de uma assistência sistematizada. Todavia, esses profissionais também assumem que as atividades burocráticas são justificativas para a não operacionalização da SAE, como podemos observar nas falas a seguir: $A$ dificuldade que a gente tem é essa, fica muito preso a abrir prescrição, a providenciar transporte de transferência, [...]. Ligar pra clínicas pra solicitar ultrassom. Então, a parte muito burocrática, muitas vezes a gente entra e sai do plantão sem olhar o paciente. A gente tá apegada a coisas burocráticas que teria que ser outro profissional para a parte burocrática e não a enfermagem, então a gente fica muito sobrecarregada deixando a desejar realmente na assistência para com o paciente (E-13); Pra mim a importância da SAE é que, é... é tipo uma fiscalização que vai ter um controle com a equipe, ta entendendo? Se ele tivesse em prática a gente tinha mais respaldo com a equipe. A importância mesmo é que a gente vai ter uma maior organização (E-22).

\section{Categoria 3 - A formação de nível médio em enfermagem:} competências e habilidade para o desenvolvimento do PE

Nessa categoria, foi possivel observar que os profissionais de nível médio apresentam desconhecimento sobre a SAE e o $\mathrm{PE}$, como sugerem as falas abaixo: $P E$... não, ainda não ouvi falar não. [...] Não, se falaram [no decorrer do curso técnico] eu já me esqueci. Já esqueci, não vou mentir ( $T$-7); O que é o processo? É cuidar da saúde, eu acho que seja cuidar da saúde do paciente. Tem mais alguma coisa? (T-17); Esse processo até o momento não estou lembrado! Esse PE (A-1).

Quando perguntamos sobre o conhecimento das etapas do $\mathrm{PE}$, foi notório que os profissionais de nível médio não sabiam citá-las, evidenciando não ter sido um conteúdo abordado na formação. Pôde-se inferir que as expressões SAE e PE não fazem parte do cotidiano desses profissionais: Já ouvi falar sobre esse processo só que no momento eu não lembro, não estou lembrada assim do "processo" (T-4); Não. Desconheço (T-9); Eu tô esquecida [das etapas do PE] (A-2).

\section{DISCUSSÃO}

Existe uma problemática identificada na definição dos conceitos de SAE e PE, por parte dos enfermeiros e da totalidade dos técnicos e auxiliares entrevistados. O desconhecimento sobre o tema pode ser explicado pela falta de informação da legislação. Ainda pode ser esclarecido, como evidenciado na literatura ${ }^{(9)}$, pela disparidade de conceitos abordados e a falta de uniformização.

Apesar da regulamentação pelo Cofen, a expressão tal como é conhecida e divulgada hoje (SAE) não é o único modo de ser chamada. São encontradas na literatura outras terminologias, como: Processo de Enfermagem, Processo de Cuidado, Metodologia da Assistência de Enfermagem, Processo de Assistir ou Consulta de Enfermagem ${ }^{(9)}$. A Resolução no 358/2009 esclarece e define o que é a SAE 
e o que é o PE, sendo este último, sinônimo de consulta de enfermagem ${ }^{(2)}$.

Com isso, a depender do conceito abordado, podem surgir dúvidas no momento da aplicação do PE, o qual aparece nas falas dos enfermeiros como sinônimo de SAE. Quanto aos auxiliares e técnicos, o desconhecimento sobre a SAE e o PE pode ser explicado pela falta de esclarecimentos quanto a sua participação nas etapas de coleta de dados, implementação e avaliação correspondentes ao $\mathrm{PE}$, conforme preconizado na mesma Resolução(2)

A participação dos auxiliares e técnicos nesta metodologia ainda é obscura; eles não percebem suas contribuições, fato reforçado pela compreensão dúbia da legislação(10), ou ainda pela falta de credibilidade desses profissionais frente à SAE e ao PE e a pouca vontade dos gestores em implantá-la(11).

Existe um conhecimento superficial dos enfermeiros sobre a conceituação da SAE e do PE, o que deixa explícito o distanciamento existente entre os profissionais e a legislação. Reiterando achados da literatura ${ }^{(12)}$, o desconhecimento sobre a SAE é visto como um desafio para a equipe, e a falta de embasamento teórico atinge diretamente a qualidade do cuidado(5) É necessário o aperfeiçoamento do ensino, de maneira a trazer tais conceitos para o cotidiano e não deixálos apenas na teoria.

Importante ressaltar que, para além de todas essas ferramentas, é necessário também a vontade e dedicação por parte da equipe de enfermagem e, acima de tudo, que esta conte com o apoio institucional a possibilitar a reorganização do serviço, a alocação de recursos humanos e materiais, priorizando-se, a assistência. Assim, a proposta de implantação da SAE deve estar de acordo com a missão, cultura, filosofia e os objetivos da instituição(13).

Apesar de alguns enfermeiros possuirem certo conhecimento sobre a SAE e o PE, apenas dois conseguiram expressar a importância destes para a qualidade do cuidado. A individualização da assistência prestada ao paciente é uma prerrogativa da aplicação do $\mathrm{PE}$, de modo a colocar em prática os seus conhecimentos, conquistando o reconhecimento pela qualidade da assistência ${ }^{(3)}$.

Como fatores dificultadores para a sistematização, foram citados a falta de materiais e o aprisionamento do enfermeiro às questões burocráticas. Em sua rotina, os enfermeiros exercem diversas atribuições que os distanciam da assistência direta ao paciente. Como fatores intervenientes que afetam diretamente a execução prática da SAE e do PE já foram citados: a falta de apoio da gerência dos serviços de saúde, recursos físicos, apoio da equipe de enfermagem, recursos financeiros, planejamento e otimização do tempo entre as ações do cuidar e a parte burocrática ${ }^{(14)}$.

Ainda sobre as questões que dificultam a implementação, foi citado o quantitativo insuficiente de profissionais. Esse dado corrobora pesquisas recentes ${ }^{(5,13,15)}$ que afirmam que a aplicação do PE tem sofrido interferência direta da sobrecarga de trabalho, associada ao número reduzido de profissionais. Vale ressaltar que o dimensionamento de pessoal, quando de acordo com as necessidades da unidade, proporciona ao profissional maior oportunidade para organizar, executar e avaliar os planos de cuidado, sendo um fator preponderante para que a SAE seja implementada(16).

Foi possivel perceber que o desconhecimento dos conceitos, pela totalidade dos profissionais de nível médio, está relacionado à formação. Outra pesquisa demonstrou resultado semelhante e sugere como fator determinante o conhecimento fragmentado oferecido nos cursos técnicos ${ }^{(17)}$. Existe de fato a necessidade de inclusão da temática na sua matriz curricular, de maneira que venha a esclarecer o papel de cada membro da equipe ${ }^{(10)}$.

É necessário fazer valer as competências profissionais, instituídas nas Diretrizes Curriculares Nacionais para a Educação Profissional de Nivel Técnico(18), a exemplo de: identificar a estrutura e organização do sistema de saúde vigente; planejar e organizar o trabalho na perspectiva do atendimento integral e de qualidade; realizar trabalho em equipe, correlacionando conhecimentos de várias disciplinas ou ciências, tendo em vista o caráter interdisciplinar da área; interpretar e aplicar normas do exercício profissional e princípios éticos que regem a conduta do profissional de saúde, dentre outras.

Importante salientar que esta última competência citada, nos remete ao que diz a Resolução no 358/2009 - Art. 5ㅇque define que o Técnico e o Auxiliar de Enfermagem participam da execução do PE, naquilo que lhes couber, sob a supervisão e orientação do Enfermeiro, em conformidade com o disposto na Lei do Exercício e o decreto que a regulamenta ${ }^{(2)}$.

Nas Diretrizes Curriculares ${ }^{(18)}$, ao tratar da formação de nível médio, não há referência ao conceito de $\mathrm{PE}$, contrariando o que legisla a Resolução 358/2009. Daí a importância de estimular os técnicos e auxiliares a participarem do planejamento do cuidado ${ }^{(17)}$.

Os técnicos e auxiliares não conseguem perceber a sua participação na execução do $\mathrm{PE}$, sendo possivel inferir que existe uma interpretação equivocada da Lei do Exercício Profissional(17) especialmente quando afirmam que a SAE é privativa do enfermeiro. A Resolução 358/2009 esclarece que o PE é uma ferramenta que operacionaliza a SAE e que o auxiliar e técnico participam do $P E^{(2)}$ por meio da efetivação da prescrição de enfermagem, convertendo-a em ações práticas, que visam repercutir positivamente na saúde da clientela ${ }^{(13)}$.

Diante do exposto, é notória que a participação destes 
profissionais na SAE ainda é limitada, e isso pode ser explicado por lacunas existentes na sua formação inicial e ao longo da trajetória profissional(19).

Considera-se oportuno apontar como limitação do estudo a realidade de apenas uma instituição, podendo não permitir generalizações. Pensa-se, contudo, que seja possivel contribuir para aprofundar o conhecimento e a reflexão sobre a temática.

\section{CONCLUSÃO}

Conclui-se que existe um déficit quanto ao conhecimento do que é a SAE e de como o PE pode contribuir como ferramenta prática para sistematizar o cuidado. Pode-se observar que essa deficiência perpassa um contínuo da formação à prática profissional, com grande necessidade de maior ênfase na formação de nível técnico e acadêmico em prol de maior aprendizagem e esclarecimentos quanto aos conceitos de SAE e PE, de maneira mais metodológica do que decorativa.

É necessário perceber o quanto a formação influencia diretamente o processo de implantação da SAE e do PE. Apesar de ser uma temática discutida na academia, se faz necessário que, nos cursos de formação de nível técnico, os docentes consigam esclarecer o papel e a atuação dos técnicos e auxiliares na execução do PE, de acordo com o que preconiza a Resolução 358/2009 para que fique clara a sua ativa participação na equipe.

\section{AGRADECIMENTOS}

Agradecemos a Pró-Reitoria de Pesquisa e Extensão da UNEB e a FAPESB, pelo auxílio financeiro.

\section{REFERÊNCIAS}

1. Garcia, TR, Nóbrega MML. Processo de enfermagem: da teoria à prática assistencial e de pesquisa. Esc. Anna Nery. 2009; 13(1):816-8.

2. Conselho Federal de Enfermagem (BR). Resolução 358/2009 do COFEN, 15 de outubro de 2009 (BR). 2009 [Citado 2015 jul 26] Disponivel em: http:// www.cofen.gov.br/resoluo-cofen-3582009_4384.html

3. Silva RS, Pereira A, Conceição JC, Biai ISC. Aplicação do processo de enfermagem: estudo de caso com um portador do virus da hepatite C. Rev Baiana Enferm. 2010; 24(1, 2, 3): 87-95

4. Menezes SRT, Priel MR, Pereira LL. Autonomia e vulnerabilidade da enfermeira na prática da sistematização da assistência de enfermagem. Rev Esc Enferm USP. 2011; 45(4):953-8.

5. Medeiros AL, Santos SR, Cabral RWL. Sistematização da Assistência de Enfermagem: dificuldades evidenciadas pela teoria fundamentada nos dados. Rev. enferm. UERJ. 2013; 21(1):47-53.

6. Silva EGC, Oliveira VC, Neves GBC, Guimarães TMR. Nurses' knowledge about nursing care systematization: from theory to practice. Rev Esc Enferm USP. 2011; 45(6):1380-6.

7. Botelho J, Veloso GBL, Favero L. Sistematização da assistência de enfermagem: o conhecimento da equipe de enfermagem de um centro cirúrgico. Rev Enfermagem em Foco. 2013; 4(3,4):198-201.

8. Bardin L. Análise de Conteúdo. Lisboa: Edições 70; 2010.

9. Silva RS, Bandeira WCO, Lima MOM. Sistematização da Assistência de Enfermagem: do que estamos falando? In: Silva RS, Bittencourt IS, Paixão GPN. Enfermagem avançada: um guia para a prática. Salvador: Sanar, 2016. 65-88.

10. Ramos LAR, Carvalho EC, Canini SRMS. Opinião de auxiliares e técnicos de enfermagem sobre a sistematização da assistência de enfermagem. Rev Eletr Enf. 2009:11(1):39-44.
11. Medeiros AL, Santos SR, Cabral RWL. Desvelando dificuldades operacionais na sistematização da assistência de enfermagem na perspectiva da Grounded Theory. Rev. Eletr. Enferm. 2013;15(1):44-53.

12. Carvalho ACTR, Oliveira KT, Almeida RS, Souza FS, Menezes HF. Refletindo sobre a prática da sistematização da assistência de enfermagem na unidade de terapia intensiva. Rev. pesq. cuid. Fundam. 2013; 5(2):3723-9.

13. Soares, MI, Resck, ZMR, Camelo SHH, Terra FS. Gerenciamento de recursos humanos e sua interface na sistematização da assistência de enfermagem. Enferm. glob. 2016; 15(42):353-64.

14. Oliveira KF, Iwamoto HH, Oliveira JFO, Almeida DV. Sistematização da Assistência de Enfermagem na Rede Hospitalar de Uberaba-MG. Rev. Enf Ref. 2012; 3(8):105-14

15. Dias I, Terra AA, Machado JO, Reis V. Sistematização da Assistência de Enfermagem no Gerenciamento da Qualidade em Saúde. Rev Baiana Enferm. 2012; 25(2):161-72.

16. Maya CM. Simões ALA. Implicações do dimensionamento do pessoal de enfermagem no desempenho das competências do profissional enfermeiro. Rev Bras Enferm. 2011; 64(5):898-904.

17. Cruz AMP, Almeida MA. Competências na formação de Técnicos de Enfermagem para implementar a Sistematização da Assistência de Enfermagem. Rev Esc Enferm USP. 2010; 44(4):921-7.

18. Ministério da Educação(BR), Conselho Nacional de Educação. Resolução № 4 de 22 Dez 1999: diretrizes curriculares nacionais para a educação profissional de nivel técnico. 1999 [Citado 2015 jul 26]. Disponivel em: http:// www.mec.gov.br/cne/pdf/CEB04991.pdf

19. Longaray VK, Almeida MA, Cezaro P. Processo de enfermagem: reflexões de auxiliares e técnicos. Texto contexto-enferm. 2008; 17(1):150-7. 